Claremont Colleges

Scholarship@ Claremont

CMC Faculty Publications and Research

CMC Faculty Scholarship

$1-1-2007$

\title{
Between The Bounds of Experience and Divine Intuition: Kant's Epistemic Limits and Hegel's Ambitions
}

James Kreines

Claremont McKenna College

\section{Recommended Citation}

Kreines, James. "Between the Bounds of Experience and Divine Intuition: Kant's Epistemic Limits and Hegel's Ambitions." Inquiry 50.3 (2007): 306-334.

This Article - postprint is brought to you for free and open access by the CMC Faculty Scholarship at Scholarship @ Claremont. It has been accepted for inclusion in CMC Faculty Publications and Research by an authorized administrator of Scholarship @ Claremont. For more information, please contact scholarship@cuc.claremont.edu. 


\title{
Between the Bounds of Experience and Divine Intuition: Kant's Epistemic Limits and Hegel's Ambitions
}

\author{
JAMES KREINES \\ Yale University, USA \\ Between The Bounds of Experience and Divine Intuition: Kant's Epistemic Limits \\ and Hegel's Ambitions. Inquiry 50:3 2007306 - 334.
}

Please cite the published version. What follows is a final draft:

\begin{abstract}
Hegel seeks to overturn Kant's conclusion that our knowledge is restricted, or that we cannot have knowledge of things as they are in themselves. Understanding this Hegelian ambition requires distinguishing two Kantian characterizations of our epistemic limits: First, we can have knowledge only within the "bounds of experience." Second, we cannot have knowledge of objects that would be accessible only to a divine intellectual intuition, even though the faculty of reason requires us to conceive of such objects. Hegel aims to drive a wedge between these two characterizations, showing that we can have knowledge beyond Kant's bounds of experience, yet without need of divine intuition. And attention to such knowledge is supposed to show that we have no legitimate need to even conceive of divine intuition and its objects - and no need to conclude that our own knowledge is restricted by comparison, or that we cannot know things as they are in themselves. I focus here on the initial case Hegel uses to introduce this extended argument strategy: we can have more knowledge of natural kinds and laws than would be allowed by Kant's bounds of experience.
\end{abstract}

Recent work on Hegel lacks consensus concerning the central ambitions of his mature project in theoretical philosophy. It is at least widely agreed that Hegel's ambitions are closely tied to his rejection of Kant's famous claim about our epistemic limits: Kant denies that we can have theoretical knowledge of things as they are in themselves; Hegel seeks, in response, to show that our knowledge is not restricted or limited in Kant's sense. But there is a surprising divergence between two recently popular approaches to this central Hegelian ambition.

A straightforward and popular approach is to read Hegel as seeking to surpass Kant's restriction: Hegel seeks to show that there are real things, or real aspects of the world, which can be known only by going beyond Kant's limits; and to show that we ourselves have access to this knowledge, or knowledge of things as they are in themselves. Of course, Kant criticizes prior metaphysics for aspiring to knowledge of things in themselves, so it is no surprise that some read Hegel as seeking to revive a form metaphysical project pursued by Kant's predecessors; for example, some see Hegel as advocating a modified version of Spinoza's monism. ${ }^{1}$

There is in addition a very different alternative, also popular recently, and sometimes referred to as a "non-metaphysical" or "post-Kantian" interpretation of Hegel. The idea is that Hegel seeks 
to advance yet farther Kant's revolution against pre-critical metaphysics. To begin with, Kant denies that we can have the kinds of knowledge to which pre-critical metaphysics aspires, and Hegel agrees. But Hegel seeks to take Kant's denial yet farther: Hegel denies also all need to even conceive of Kant's things in themselves, leaving no contrast relative to which our own knowledge could be said to be merely limited or restricted. That is, Hegel aims not to surpass Kant’s restriction so much as to eliminate that restriction from the inside.?

But it is striking that Hegel's Logic and Encyclopedia sometimes suggest both the goal of eliminating from within and the goal of surpassing Kant's epistemic limits. For example, at one point Hegel dismisses the very idea of things in themselves: "they are as such nothing but truthless, empty abstractions." And yet the very next sentence adds that there is another sense in which Hegel's Logic aims to establish knowledge of things as they are in themselves: "What, however, the thing in itself is in truth, what truly is in itself, of this logic is the exposition" (WL 5:130/121). Of course, it can be difficult to understand how anyone could coherently seek to eliminate the very idea of things in themselves while also seeking to establish knowledge of real things in themselves. But I argue that Hegel does have a way of joining these seemingly divergent ambitions together, so that they provide the two basic and equally important goals of his overall project in theoretical philosophy.

I begin (section 1) by distinguishing two different Kantian characterizations of the limits of our knowledge: One can, first, view our epistemic limits from within, specifically by asking: Whatcan we know? We can have knowledge only within the "bounds of experience," or within the bounds delimited by our sensible intuition. But why conclude on this basis that we are limited, or unable to know things as they are in themselves? While Kant has more than one kind of answer, the answer of greatest importance for Hegel is found in the argument of the "Transcendental Dialectic" from the Critique of Pure Reason. Here Kant argues that the faculty of reason guides our theoretical inquiry by providing a goal: knowledge of the "unconditioned." Further, such knowledge would be possible only for a higher, even divine form of intellect-for "intellectual intuition" grasping real objects immediately, and even grasping all of reality immediately. So the faculty of reason guides us in a manner that compels us to conceive of the bounds imposed by our sensible intuition in a second manner: from beyond their reach, or as specifically restricting. What can't we know? Objects knowable only by divine intuition.

Hegel responds by trying to drive a wedge between Kant's different characterizations of our limits, opening up philosophical space between the bounds of experience and divine intuition. He will argue that we can have knowledge surpassing Kant's bounds of experience, yet without need of divine intuition grasping reality immediately and all at once. The introductory sections of Hegel's Encyclopedia focus on the specific example of knowledge of natural laws and kinds. So I consider Kant's view of such knowledge, and Hegel's initial case that we can have such knowledge beyond the extent allowed by Kant's bounds of experience (sections 3 and 4). I then turn to the basic goals of the philosophical project which begins at this point (section 5). Hegel will argue that knowledge of natural laws and kinds and is just an initial example of the considerable explanatory knowledge we can have beyond Kant's bounds of experience, or knowledge (in this sense) of things as they are in themselves. And Hegel will seek to show that our access to such knowledge beyond Kant's bounds, in this and further cases, leaves us without any grounds for thinking that the guiding goal of our theoretical inquiry is a kind of knowledge 
that is in principle unattainable. So Hegel will conclude that there is no remaining need to even conceive of objects knowable only by divine intuition, and that our own knowledge is subject to no fundamental limitation or restriction. In other words, Hegel seeks to establish knowledge of "things in themselves” (in the sense of explanatory knowledge beyond Kant's bounds) precisely in order to dismiss the very idea of "things in themselves" (in the sense of objects knowable only by divine intuition). Or, Hegel seeks to surpass Kant's bounds of experience precisely in order to eliminate from within the idea of a limitation relative to divine intuition.

Finally, I aim here to avoid the sort of interpretive charity that would begin with a favored contemporary view and then seek to find that view in historical texts. I think that such an approach tends to obscure differences between contemporary views and the views of historical figures, as well as differences between different historical figures. My own position is that the theoretical philosophies defended by Kant and Hegel are very different, and that both have philosophical benefits as well as costs. I make no attempt here at a comprehensive weighing of costs and benefits, or a final judgment in favor of Kant or Hegel. And, of course, I cannot here explain and defend all of the arguments by which Hegel seeks to achieve the ultimate objectives of his theoretical philosophy. My concern is to show that Hegel is surprisingly successful at integrating seemingly divergent ambitions into a single, coherent, and philosophically interesting argument strategy, proposed in the introductory sections of the Logic and Encyclopedia, and directed against Kant's case for the conclusion that our knowledge is fundamentally limited or restricted.

\section{Kant on Reason and the Limitation of Our Knowledge}

I begin with a sketch of the argument for the limitation of our knowledge found specifically in Kant's account of the faculty of reason from the "Transcendental Dialectic.” Kant here advances an account of the faculty or capacity supposed to be responsible for our interest in explanatory knowledge, and for providing the guiding goal for all our theoretical inquiry. More specifically, we do not rest content with knowledge, provided by "the understanding," of what is the case in the empirical world. We seek to know why such-and-such is the case; we seek to explain. In order to account for this, the faculty of reason itself must be itself be characterized by an "aim" or “end” (Zweck), or even an "interest” (Interesse): insofar as we are rational, we take an interest in underlying grounds or conditions of all kinds, or in following a "regress from the conditioned to its condition" (A523/B521). And not just to an arbitrary degree: we seek to follow the regress to completion, or to achieve knowledge of the unconditioned. In short, "the proper principle of reason in general ... is to find the unconditioned for conditioned cognitions of the understanding” (A307/B364).

But Kant holds, throughout the critical period, that we can have knowledge only within the "bounds of experience.” Kant's line of argument is as follows: Analytic judgments cannot extend our knowledge but only clarify our concepts (A7-8). Synthetic, knowledge-extending judgments about objects require intuition: "all synthetic judgments of theoretical cognition are possible only by the relating of a given concept to an intuition" (C 11:39). And we are dependent on sensibility for intuition. In Kant's terms, our "understanding” is merely "discursive," which is to say that it "can only think and must seek the intuition in the senses" (B135). So we can extend our knowledge only in cases where intuitive content can be provided by sensibility. Kant writes: 
No concept can have its objective reality be secured, save insofar as it can be presented in a corresponding intuition (which for us is always sensory), so that beyond the bounds of sensibility and thus of possible experience, there can be no cognition whatever, that is, no concepts of which one is sure that they are not empty. (UE 8:188-9)

The limits of our experience and knowledge, then, are delimited specifically by the bounds of sensibility. And so they are delimited by the a priori forms of our sensibility: space and time. ${ }^{3}$ We can have empirical synthetic knowledge of objects only where there is possible empirical intuition, conditioned by those forms. And we can have a priori knowledge only where intuitive content is provided by a priori intuitions of space and time themselves. For example, the a priori intuition of space is supposed to make possible synthetic knowledge of necessary and universal truths of geometry. Synthetic priori knowledge of the necessary conditions of the possibility of experience is similar. For example, the "Second Analogy" establishes that "all alterations occur in accordance with the law of the connection of cause and effect" (B232). This result is not supposed to be proven "dogmatically, i.e. from concepts"; it is synthetic in virtue of its connection to time: the analogies articulate "a priori conditions of the thoroughgoing and necessary time-determination” (A216-7/B263-4). ${ }^{4}$

These bounds of experience prevent knowledge of anything truly unconditioned. First, consider the possibility that there really exists an absolutely unconditioned first condition on which a whole series of conditions depends. This first condition could not be an event in time, as it would then have to be conditioned by a prior cause; and it could not be an object in space, as it would

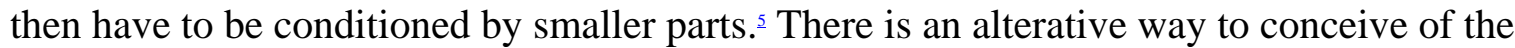
unconditioned: an infinite series without any first condition might still be such that thetotality of the series grounds or conditions all of the members, so that "their whole is absolutely unconditioned" (A417/B445). But such a totality cannot be anything in space and time without, again, being merely conditioned. Further, corresponding intuitive content cannot be generated in this case: there can be no completion of a stepwise "successive synthesis" of the "manifold of sensible intuition" in space and time for knowledge of an infinite totality. ${ }^{6}$ In sum, then, the forms of our sensible intuition prevent all possibility of knowledge of the unconditioned: "in sensibility, i.e. in space and time, every condition to which we can attain in the exposition of given appearances is in turn conditioned" (A508/B536). And in demanding that we seek knowledge of "the unconditioned," the faculty of reason is pointing or aiming us specifically "beyond the boundaries of experience" (Bxx).

We can understand in these terms a central strategy in Kant's attacks on previous forms of metaphysics. For example, Leibnizian rationalists wish to draw conclusions about an absolutely inner nature of things, and Kant anticipates their complaint that he allows "no insight” here. Kant's response is that asserting knowledge of a real and absolutely inner nature of things, as opposed to claims merely clarifying the implications of our concepts, would require intuition, but not an intuition possible for our sensibility:

They would have us be able to cognize things, thus intuit them, even without senses, consequently they would have it that we have a faculty of cognition 
entirely distinct from the human not merely in degree but even in intuition and kind.

Such an intellect could be possessed "not by humans but beings that we cannot even say are possible, let alone how they are constituted” (A277-8/B333-4). So Kant will argue that the bounds of experience, delimited by our sensible intuition and its forms, prevent the legitimate assertion of such metaphysical claims.

As this last citation makes clear, Kant does claim that we can conceive of a higher form of cognition or intellect different in kind, at least to some degree, by contrasting our own. Such cognition would require a non-sensible form of intuition, or "intellectual intuition"-which would bypass the mediating conditions of our sensible intuition, providing immediate access to reality. If there is a non-spatio-temporal first condition on which a series of conditions depends, then knowledge of it would be possible for an intellect bypassing the mediating conditions of our sensibility, space and time. And this first kind of immediacy would bring along another sense of immediacy: intellectual intuition could grasp together immediately even an infinite totality of conditions, without having to work stepwise through successive synthesis of a manifold of intuition. So, as Kant emphasizes in the Critique of the Power of Judgment (KU), if there is an absolutely unconditioned totality, then a higher form of "intuitive understanding" could have knowledge of it. ${ }^{-}$When I refer here to "divine" intuition, I am referring to the two kinds of immediacy which would eliminate the barriers blocking our knowledge of the unconditioned: intellectual intuition "would grasp and present the object immediately and all at once (unmittelbar und auf einmal)” (TP 8:389). (I will not consider here Kant's further claim that such an intellect would also have to be divine in the sense that its own thoughts would immediately bring their objects into being. ${ }^{9}$ )

Despite our inability to know anything unconditioned, Kant argues that ideas of the unconditioned play a necessary and legitimate role in all our theoretical inquiry. In Kant's terms, reason's demand that we seek the unconditioned is necessary and legitimate as a "regulative principle" guiding our inquiry, but not as a "constitutive principle" which would extend our knowledge to the unconditioned, or "beyond all possible experience" (A509/B537). In the appendix to the "Transcendental Dialectic," Kant applies the point to natural scientific inquiry. Here ideas of the unconditioned are supposed to "have an excellent and indispensably necessary regulative use, namely that of directing the understanding to a certain goal” (A644/B672).

Finally, this account of reason plays a crucial role supporting Kant's transcendental idealism. Kant's canonical formulations of this view take the form of a claim about all objects of our knowledge, or "everything intuited in space and time, hence all objects of an experience possible for us": these are "appearances" as opposed to things as they are in themselves..$^{10}$ We do not need to resolve here the many controversies concerning this doctrine, but only to note the feature emphasized by Ameriks: transcendental idealism and Kant's arguments for it turn on specific reference to our sensible intuition and to its specific forms, space and time. ${ }^{11}$ Kant sometimes emphasizes this by contrasting divine intuition, for example: "in the Critique of Pure Reason we had to have in mind another possible intuition if we were to hold our own to be a special kind, namely one that is valid of objects merely as appearances” (KU 5:406). But what are Kant's reasons for his conclusion? In particular, we are supposed to be unable to know that there really 
is divine intuition, or things knowable only thereby; so why should we conclude that our own sensible intuition is limiting, or that it prevents knowledge of things as they are in themselves?

The Critique of Pure Reason is supposed to provide two basic kinds of arguments for transcendental idealism (Bxviii-xxii and A506/B534). The first kind aims to establish that only transcendental idealism can explain the possibility of synthetic a priori knowledge (Bxviii-xix). But there is also a second kind of argument, based on the account of reason. The basic idea is easy to appreciate: we must conclude that our own sensible intuition and its forms are limiting insofar as they preclude our reaching the guiding goal that we ourselves seek in all theoretical inquiry. Kant sketches the argument in this way:

That which necessarily drives us to go beyond the boundaries of experience and all appearances is the unconditioned, which reason necessarily and with every right demands in things themselves for everything that is conditioned.

True, we cannot know that there really is anything unconditioned. But precisely because we must conceive and cannot know the unconditioned, we must conceive of it as "present in things insofar as we are not acquainted with them, as things in themselves." Otherwise, "the unconditioned cannot be thought at all without contradiction" (Bxx). Otherwise, that is, tensions between the idea of the unconditioned and the constraints imposed by our form of cognition will drive us to the contradictions discussed in the first two "Antinomies". So we must distinguish the objects of our knowledge from things as they are in themselves, and conclude that our knowledge is limited or restricted.

\section{The Goal of Eliminating One Kantian Limit by Surpassing Another}

My own view is that Kant's account of the faculty of reason, and the conclusions it is supposed to support, have real philosophical advantages that would be worth attention in their own right. But my aim here is not to further interpret or defend this material in Kant; it is to understand Hegel's response.

One simple and straightforward way of rejecting Kant's limits would be to claim to surpass all of the limits he sets. For example, one might assert knowledge that there is some kind of highest being knowable only by grasping reality immediately and all at once. This may be the best way to understand Hegel's own earliest philosophical publications, dating from the short period of his collaboration with Schelling in Jena; Longuenesse, for example, reads Hegel's 1802 article "Faith and Knowledge" as claiming that "God's knowledge is accessible to finite consciousness" (2000, 263). But Hegel’s earliest publications, his break with Schelling, and his early development are all topics beyond my scope here. I limit my focus here to the philosophical project of Hegel's later writings, especially as this project is introduced and defended in the early sections of the Logic (1812-16) and Encyclopedia (1816-30; I refer here to the 1830 edition). Here Hegel places tremendous stress on a very general criticism of claims about highest beings (or somehow most fundamental aspect of reality) supposed to be knowable only by divine intuition grasping reality immediately and all at once..$^{12}$ 
For example, already the "Preface" of the Phenomenology of Spirit (1807) complains about "a view which is in our time as prevalent as it is pretentious": the view that "the true exists only in what, or better as what, is sometimes called intuition, sometimes immediate knowledge of the absolute, religion, or being" (PG 3:15/4). The beginning of the Encyclopedia includes a section meant to characterize the philosophical views most popular among Hegel's own contemporaries; here Hegel claims that his contemporaries generally appeal to one or another form of "immediate knowledge” (§61-§78). Hegel takes Jacobi as paradigmatic, but he casts a wide net (§63An). Elsewhere he includes others: for example, Schelling, "like Jacobi, makes his principle immediate knowledge - the intelligent intuition” (VGP 20:427/3:519). Hegel's goal here is to bring out a similarity among views that will also differ in other respects. Perhaps there are also other respects in which Hegel himself is influenced by some of these views. But Hegel argues that such views share one specific feature which is itself philosophically unacceptable: Any appeal to "immediate knowledge" must claim neither to admit nor to require the mediation of a justification - whether a justification by empirical experience, by philosophical argument, or anything else. To appeal to immediate knowledge, then, is to hold that all required justification is contained with the act of knowing itself. But this can only by "subjective knowing," so that "the factum of consciousness ... has been made into the criterion of truth" (§71). And by this standard any "superstition or idolatry" might equally be "proclaimed as truth" (§72). If we were willing to allow that, then there would be no reason to bother with philosophy. Philosophy, by contrast, must "not tolerate any mere assurances or imagining” (§77). Hegel elsewhere deploys the same basic argument against Schelling: "One wants, if one philosophizes, to have proven that it is so"; but with Schelling's appeal to intellectual intuition, "the proving of anything, the making it comprehensible, is thus abandoned." ${ }_{13}$

While there are complex questions concerning the accuracy of Hegel's interpretations of his contemporaries, and perhaps rejoinders to his attack, Hegel's line of argument certainly clarifies his own philosophical goals. In short, Hegel's complaint draws on a familiar Kantian commitment: "our age is the genuine age of criticism," Kant says, "to which everything must submit" (Axi). Hegel's complaint is that appeals to "immediate knowledge" involve a refusal to submit to criticism. With Jacobi, for example, "that immediacy is grasped as absolute, manifests a lack of all criticism, all logic"; and Hegel says that his contemporaries generally move "beyond the Kantian philosophy" not by going "forward" but rather by going "backward" to the "procedure of the older metaphysics, an uncritical thinking on and on." ${ }^{14}$

Of course, Hegel himself is no orthodox Kantian: Hegel will argue, against Kant, that our knowledge is not fundamentally limited or restricted. But we must understand this desired conclusion here in manner consistent with Hegel's claim to carry the Kantian philosophy farther "forward." More specifically, Kant denies the possibility of knowledge of objects of divine intuition; Hegel seeks to push this critical denial yet farther, turning it against Kant himself: Hegel will argue that we have no need or legitimate reason even to conceive of objects knowable only by divine intuition, leaving no legitimate sense in which our own knowledge would be fundamentally limited or restricted by comparison.

Before turning to Hegel's argument for this desired conclusion, consider further the meaning of the conclusion itself. To begin with, it makes sense for Hegel to call Kant's idealism as a form of "dualism," at least in this specific and limited sense: whatever else we say about it, Kant says 
that his idealism rests on a distinction between two forms of intellect supposed to be utterly different in kind. . $^{15}$ To be sure, Kant does not assert knowledge of the reality of a divine intuition. Rather, the conception of the unconditioned provides a guiding goal which we are required to always seek in all theoretical inquiry, and which allows continuous scientific progress while remaining in principle unreachable. So the conception of something that would be knowable only by divine intuition plays the role, in Hegel's terms, of "the ought and the infinite progress" in Kant's "dualism" (WL 5:181/163). But Hegel is an anti-dualist, in the sense that he seeks to do away entirely with even the conception of a divine intuition and of objects knowable only thereby - to show that there is no legitimate reason we need conceive of these ideas, or accord them philosophical importance.

Note that this particular form of anti-dualism pits Hegel against even some forms of monism. Consider this monist proposal: The totality of everything in this world is not truly a whole composed of smaller parts in space, or something merely conditioned by its parts; if we could break beyond our ordinary ways of knowing things in space and instead grasp immediatelytogether the whole of everything, we would find that the totality provides an absolutely unified and unconditioned ground for all reality. ${ }^{16}$ Hegel must and does reject such forms of monism. In Kant's terms, "the idea of absolute totality" is "valid only as a condition of things in themselves" (A506/B534). And Hegel treats the idea of an absolutely unconditioned and unified totality as the idea of a "thing in itself" in the specific sense that it is the idea of something knowable only by divine intuition grasping reality immediately and all at once. In Hegel's terms, "the thing in itself is the same as that absolute of which we know nothing except that in it all is one." And Hegel, first of all, follows Kant in denying the possibility of knowledge of such things in themselves. What's more, Hegel seeks to argue for the further conclusion that there is no legitimate reason even to take such ideas seriously: "things in themselves" in this sense are "as such nothing but truthless, empty abstractions” (WL 5:130/121).

Hegel states this goal in more general terms in the introductory sections of the Logic. The idea of a "thing in itself," at least in the sense of any object supposed to be available only to divine intuition, is a "sheer beyond of thought" (WL 5:37/45): the content for this idea is provided by a contrast with or abstraction from the objects we ourselves can think, cognize, and know. Hegel seeks to show that there is no legitimate philosophical role to be played by that idea. He sides with those who have "recognized the nothingness of the spectral thing in itself left over from the Kantian philosophy ... and intended to destroy it completely"; Hegel wants a new approach that can finally bring this destruction "to a successful conclusion" (WL 5:41/47). Alternatively, he aims to show that "these things which are supposed to stand beyond us ... are themselves figments of thought ... the so-called thing in itself of empty abstraction” (WL 5:26/36).

But it is one thing to grasp Hegel's goal here, and it is another to understand the arguments by means of which he hopes to achieve that goal. To say that Kant's view is in one sense a form of "dualism" is not to demonstrate that there is anything wrong with it. Furthermore, from the claim that we can know nothing about the objects of divine intuition it does not follow that ideas of such objects must be empty, meaningless, empty abstractions, illegitimate, idle, or of no importance. It is after all part of Kant's own point to insist on our lack of knowledge, while arguing that we have other reasons for taking seriously such ideas-and so other reasons for distinguishing objects of our knowledge from things as they are in themselves. If Hegel is to 
conclude that our knowledge is not fundamentally limited or restricted, then he must meet Kant's argument with philosophical arguments of his own.

Hegel's argument strategy will turn on his attempts to show that we can have knowledge exceeding Kant's bounds of experience, yet without need divine intuition grasping reality immediately and all at once. That is, Hegel will try to show that Kant's distinction between our own cognition and divine cognition is a false dichotomy. In Hegel's terms, "the antithesis between an independent immediacy of the content or of knowing, and, on the other side, an equally independent mediation that is irreconcilable with it, must be put aside” (§78). Hegel recognizes that Kant affirms "the objective validity of our empirical judgments" (A202/B247); so one cannot go beyond Kant's limits merely by reaffirming this objective validity. ${ }^{17}$ But Hegel argues that Kant's specific commitment concerning the bounds of experience would block access to a great deal of explanatory knowledge. For example, Hegel will ultimately emphasize his case, against Kant, that we can have explanatory knowledge of genuinely teleological phenomena in the case of living beings..$^{18}$ But Hegel introduces and explains his project in the Encyclopedia mainly by means of the initial example of explanatory knowledge of natural laws and kinds. So I will focus here, first, on why Kant's bounds require him to deny the possibility of knowledge of natural kinds and laws, except the laws governing all matter. And I will focus on Hegel's initial reasons for responding with linked metaphysical and epistemological claims: The metaphysical claim is that there are more laws than just the most general laws governing all matter-there are determinate laws governing specifically distinct natural kinds. And the epistemological claim is that we can have knowledge of these laws and kinds, without need of divine intuition grasping reality all at once. Hegel will later seek to complete and extend his account of explanatory knowledge beyond Kant's bounds, and of the objects of this knowledge (such as natural laws and kinds). And he will ultimately argue that we have access to so much explanatory knowledge that there is no remaining need to conceive of the goal of theoretical inquiry as a kind of knowledge that would be accessible only to divine intuition — and no need to conclude that our own knowledge is, by comparison, limited or restricted, leaving us without knowledge of things as they are in themselves.

\section{Kant on Knowledge of Natural Laws and Kinds}

Why does Kant's commitment concerning the "bounds of experience" restrict the possibility of knowledge of natural kinds and laws? On the face of it, one might have thought that natural science discovers such laws, and that all natural scientific knowledge is meant to fall within Kant's "bounds of experience.” But Kant's bounds are not delimited by ad hoc lists of sorts of knowledge meant to be included and excluded. Rather, Kant commits himself to a general principle: synthetic knowledge requires not only concepts but also "corresponding intuition (which for us is always sensory)” (UE 8:188-9). This is supposed to allow knowledge of unperceived objects which are "connected with our perceptions in a possible experience" according to the a priori laws governing all experience. It is even meant to allow knowledge of objects whose perception "is impossible for us given the constitution of our organs"-Kant mentions "magnetic matter" here-so long as these are objects of "possible experience in general," or so long as corresponding sensible intuition would be possible given "finer" sense organs (A225/B273). 
But when it comes to natural laws, Kant holds that these must be universal and necessary..$^{19}$ And for a claim about how absolutely all things of a given kind necessarily behave, there can be no corresponding empirical intuition from sensibility. Not even from a sensibility superior to ours in degree, so long as it is like ours in kind. So Kant's commitment concerning the bounds of experience, as Michael Friedman has emphasized, rules out the possibility of strictly or purely empirical knowledge of natural laws governing natural kinds; Kant's holds that "empirically one can discover rules, but not laws ... for to the latter belongs necessity, and hence that they are cognized a priori.”믄

Of course, Kant famously defends the possibility of synthetic a priori knowledge of necessity. But synthetic knowledge requires intuition. And synthetic knowledge of necessity requires $a$ priori intuition. Given Kant's bounds, this can only be the a priori intuitions of space and time, or the pure forms of our sensible intuition. As noted above, the connection to time in particular is supposed to make possible knowledge of a priori principles of time-determination, including of the law of causality: "all alterations occur in accordance with the law of the connection of cause and effect" (B232). But while it is a matter of debate whether Kant aims to prove in the "Second Analogy" that there must be determinate causal laws governing specific kinds of things, that argument certainly does not purport to establish knowledge of any particular laws. ${ }^{21}$ The law of causality and all principles of the understanding are a priorilaws of "nature in general" as opposed to "particular laws” (B165).

Kant does hold that there must be a close connection between the general principles of the understanding and particular natural laws: "without exception all laws of nature stand under higher principles of the understanding, as they only apply the latter to particular cases of appearance” (A159/B198). And Kant gives an account of how this connection or application works in the 1786 Metaphysical Foundations of Natural Science (MAN). The topic here is not supposed to be general transcendental inquiry "without any relation to any determinate object of experience"; MAN pursues rather inquiry into "a particular nature of this or that kind of thing." More specifically, Kant seeks to establish knowledge of the necessary laws governing all material objects. He does so by applying the a priori principles of the understanding to the empirical concept of matter. But it is crucial that Kant's commitment concerning the bounds of experience still imposes its constraints here. Synthetic knowledge of necessity still requires $a$ priori intuition: "it is still required that the intuition corresponding to the concept be given $a$ priori" (MAN 4:469-470). Kant holds that such knowledge is possible in the case of matter specifically because there is a special connection between the empirical concept of matter and $a$ priori intuition. He begins to make this case by claiming that everything showing up in outer sense (whose form is space) must be corporeal (4:470), and more specifically must be matter in motion $(4: 476) . \underline{22}$

MAN is more pessimistic about chemistry, specifically because of the apparent lack of connection to a priori intuition: "chemistry can become nothing more than a systematic art or experimental doctrine, but never science proper; for the principles of chemistry are merely empirical and admit of no presentation a priori in intuition.” ${ }^{23}$ But the important point here goes beyond the specific example of chemistry. Chemistry is a case in which we naturally expect laws governing not a single basic kind like matter, but rather relations between specifically distinct natural kinds, such as water as specifically distinct from other chemical kinds. There are no 
prospects for arguing that the concept water applies to everything that shows up in outer sense, thus grounding a correspondence to a priori intuition. So Kant must and does conclude that, if there are specifically distinct natural kinds of this sort, then we have no possibility whatsoever of ever coming to know their necessary natural laws. We might acquire knowledge of the laws of chemistry, but only if it can become more like physics - only if the distinct chemical kinds can be reduced to something like a single kind of matter in motion, so that for the "chemical actions of matters on one another" it would be possible that "their motions and all the consequences thereof can be made intuitive and presented $a$ priori in space” (MAN 4:470-1). ${ }^{24}$

The crucial general point here is that Kant allows no possibility of gaining knowledge of natural laws governing specifically distinct kinds. For example, in the KU:

Specifically distinct natures, besides what they have in common as belonging to nature in general, can still be causes in infinitely many ways; and each of these ways must ... have its rule, which is a law, and hence brings necessity with it, although given the constitution and the limits of our faculties of cognition we have no insight at all into this necessity (KU 5:183) $)^{25}$

Now one issue raised by this passage is this: Does Kant claim that there are real but unknowable law-governed and specifically distinct natural kinds? Or that we indispensably, usefully, and rationally believe there to be such laws and kinds, but cannot know that there are? Or does Kant take our inability to have scientific knowledge of such kinds as pure elements to specifically "preclude a scientific realist construal of those entities" (Okruhlik 1986, 313)? I would favor the intermediate answer, but I cannot resolve that issue here. For my purposes the crucial point is the denial of knowledge maintained from the first to the third Critique: (i) Kant recognizes that there are cases, as in chemistry, where we naturally expect there to be necessary laws governing specifically distinct kinds; and (ii) Kant's bounds of experience require him to deny, and he does deny, the possibility of our ever gaining theoretical knowledge of natural laws governing specifically distinct kinds.

To be sure, Kant does argue in the appendix to the "Transcendental Dialectic" that we necessarily and legitimately pursue knowledge of absolutely basic and pure underlying chemical elements, and the laws governing their interactions. This pursuit requires guidance by concepts of pure elements, which "as far as their complete purity is concerned, have their origin only in reason" (A646/B674). Here reason's goal of the unconditioned, applied to the specific challenges of explaining the complexity and diversity of nature, directs us to seek a fundamental underlying system of natural forces, laws, and kinds - a "systematic unity of nature" which would explain everything natural. We cannot reach this goal, because in pointing us toward the unconditioned, reason aims us toward a point that would fall "entirely outside the bounds of possible experience” (A644/B672). We can progress “asymptotically” (A663/B691) by simplifying the system of forces, laws and kinds we recognize as basic, while accounting in these terms for ever more phenomena-by bringing “systematic unity into cognition” (A650/B678).

But note that Kant does not here defend knowledge of necessary and universal natural laws governing relations between pure chemical elements, or any other specifically distinct natural kinds. He argues that we can approximate knowledge, or more precisely that we can have 
knowledge of "empirical rules" which approximate the status of necessary natural laws. For example, "this use of reason is only regulative, bringing unity into particular cognitions as far as possible and thereby approximating the rule to universality" (A647/B675; my emphasis). The third Critique provides a new approach to these issues, focused on the idea of "reflective judgment," but the point about approximation remains. Kant here refers to the "order of nature in its particular rules, which can only be empirically known and which are, as regards the understanding, contingent.” True, reflective judgment is supposed to provide the understanding with rational warrant allowing these particular rules to "be thought by it as laws (i.e. as necessary)." Still, with respect to such laws, "it does not and can never cognize their necessity" (KU 5:184-5). So from the first to the third Critique Kant denies the possibility of our having knowledge of particular, necessary and universal laws governing specifically distinct kinds. ${ }^{26}$ Kant's commitment throughout concerning the bounds of experience allows scientific knowledge of necessary natural laws only in those cases where we can reduce the basic concepts of natural kinds to a concept which can be shown to correspond to a priori intuition, as is supposed to be shown with the concept of matter in MAN.27

Granted, some recent readers argue that Kant, during the critical period, himself asserts knowledge of nature which oversteps his own official commitments concerning our limits, anticipating his own late "post-critical" notes for an unfinished project (the Opus postumum). ${ }^{28}$ I do not advocate this approach. But it is worth noting that, if such a reading were correct, then defending Hegel would be that much easier: one could then find support in Kant's own critical works for Hegel's challenge. Yet I seek to show that we can appreciate the philosophical appeal of Hegel's own argument against Kant's official commitments concerning the limitation of our knowledge and transcendental idealism, without having to draw on such controversial claims about Kant himself contradicting those commitments.

Finally, note that it is not regrettable but desirable, given Kant's further goals, to reach the conclusion that there are cases in which our scientific inquiry can find no stopping points in the pursuit of knowledge of laws and kinds, but can find only continual progress toward a goal that is in principle unreachable. For this conclusion contributes to the argument for transcendental idealism sketched above: Kant aims to show that theoretical inquiry seeks knowledge which is in principle inaccessible for us, and he seeks to argue on these grounds that conceiving of our own theoretical goals requires distinguishing the objects of our knowledge from things as they are in themselves.

\section{Hegel on Knowledge of Natural Laws and Kinds}

Hegel elsewhere dismisses Kant's account of the knowability of the laws governing matter. Hegel argues that Kant's a priori intuitions are themselves too indeterminate to ground knowledge of any determinate natural laws and kinds. In effect, Hegel asks: Is Kant's concept of matter just the concept of anything that could possibly be experienced in space? If so, then the laws Kant establishes will not be determinate or particular laws of nature but rather general or formal a priori laws of "nature in general," like the "principles of the understanding" established in the first Critique. If not, then we will have no a priori intuition corresponding directly to the empirical concept of matter, making knowledge of the necessary laws of allmatter impossible 
within Kant's bounds of experience. In Hegel's terms, the forces whose laws Kant claims to establish "are either ideal, in which case they are not forces, or else they are transcendent.”를

So how does Hegel argue, in the introductory sections of the Encyclopedia, that we can gain knowledge of natural laws and kinds, including specifically distinct kinds? The key is the idea that appeal to laws of nature can explain natural phenomena specifically insofar as the laws really determine or govern natural phenomena. ${ }^{30}$ And we can gain knowledge by thinking about what we observe, and drawing inferences about the natural laws and kinds which explain our observations. In Hegel's terms, "thinking things over leads to what is universal in them" (§24An). Lecture notes attached to a nearby paragraph add: "in thinking about things, we always seek what is fixed, persisting and inwardly determined, and what governs the particular" (§21Zu; my emphasis). What does govern the particular? Universal laws and kinds:

The empirical sciences do not stop at the perception of single instances of appearance; but through thinking they have prepared the material for philosophy by finding universal determinations, kinds, and laws (\$12An).

Naturally, it can be objected that the kind of "thought" which infers from experience to governing laws and kinds would be too uncertain to yield knowledge. The introductory sections of the Encyclopedia argue that such objections depend on two unconvincing commitments, both of which Hegel associates with empiricism. The first empiricist commitment is this: Sense perception sets the standard for all knowledge by providing immediacy and so certainty. If so, then one might argue that any inferences we draw beyond perception, including inferences about laws and kinds, would lack immediacy and so certainty, and would for this reason fall short of knowledge. But Hegel complains that empiricists simply assume the immediacy and certainty of sense experience. For example, "in Hume's skepticism, the truth of the empirical, the truth of feeling and intuition is taken as basic; and on that basis, he attacks all universal determinations and laws" (\$39An). Further, in rejecting the idea that we have any kind of "immediate knowledge," Hegel is committed to holding that all our knowledge, even of the objects of perception, is mediated. ${ }^{.11}$ If so, then this line of thought provides at least initial support for Hegel's alternative position: if we wish to avoid the counter-intuitive conclusion that we have no knowledge of anything at all, then we must reject the empiricist arguments that a lack of immediacy precludes knowledge of "universal determinations and laws.”

It is worth considering again Kant's position on natural laws and kinds in this connection. Kant claims that there is a boundary at which our knowledge ends; given this boundary, he can defend only the possibility of approximate knowledge of natural laws governing specifically distinct kinds. One might seek to defend Kant's view by arguing as follows: knowledge of laws and kinds is supposed to be approximate in the sense that it is fallible and revisable (e.g. Kitcher 1986, 230); and this is just what we should expect, insofar such knowledge certainly doesseem to be fallible and revisable. But this is not itself sufficient defense. To defend Kant's claim about the boundary in these terms would require also an argument that matters are different on the other side of the boundary - an argument that we have knowledge within the bounds of experience which is not fallible and revisable in any similar sense, including knowledge of perceived objects and even knowledge of the laws governing all matter. Otherwise we would have to either deny knowledge on both sides of Kant's boundary, or else admit knowledge on 
both sides. Indeed, Hegel's view is simply that there are no sharp lines dividing our insight into the objects of perception from our insight into natural laws and kinds - no line at which there is a sharp change in mediation, fallibility, revisibility, etc., so no sharp line at which knowledge might be said to end. Of course, this denial of sharp lines stems again from Hegel's anti-dualist rejection of the idea that we have any immediate knowledge at all.

Hegel also singles out a metaphysical commitment which he associates with empiricism. The commitment is this: Reality consists only of things which are entangled in no necessary connections, such as "alterations that follow one after the other" and "objects that lie side by side” (\$39). If so, then one might argue as follows: A law of nature cannot be anything like a necessary connection; a law of nature must be rather an exceptionless or universal regularity in the arrangement of things. So insofar as the arrangement of disconnected things determines which regularities hold universally, this will determine what the laws of nature are; natural laws will not govern or determine what happens, they will rather describe orsummarize. ${ }^{33}$ If so, then we cannot gain knowledge of laws by drawing inferences about what governs or determines the things we observe. One might then further argue that, in trying to discover laws of nature we can only venture uncertain estimates, from our limited observations, about what regularities might turn out to be universal; we could achieve knowledge of the laws of nature only if we could somehow experience everything - perhaps with divine intuition grasping immediately and all at once the whole of reality.

Hegel rejects the guiding metaphysical commitment here. He allows that "empirical observation ... does not provide any necessary connection” (\$39). But while empiricists may like the metaphysical view that reality entirely lacks necessary connections, their own epistemological constraints should prevent them from justifying it: if we cannot draw further inferences from perception to anything else, then we cannot draw inferences from the fact that we do not perceive necessary connection to any particular conception of "universal notions, principles, and laws"let alone to a view about the nature of all reality. So Hegel complains about any "empiricism" holding that "these universal determinations ... are not supposed to have any more significance and validity on their own account than that which is taken from perception” (§38An). And Hegel argues that empiricism here puts forward a general metaphysics, but "without knowing that it thereby itself contains a metaphysics” (§38An)—and so without providing the sort of support such a view would require.

Note that if Hegel is right that these empiricist commitments are without convincing support, then neither can provide any reason to reject our intuitions about the nature and knowability of natural laws and kinds. And those intuitions can provide at least initial support for Hegel's view. In particular, say one accepts the intuition that appeal to natural laws can explain particular natural phenomena specifically insofar as those laws truly govern or determine the particular phenomena (rather than merely describing or summarizing regularities). Similarly, say one accepts the intuition that appeal to natural laws explain particular natural phenomena by grouping them into determinate kinds governed by the uniform laws-rather than being restricted to governing each individual case differently, or being restricted to governing all of nature as a single maximally abstract kind. Such intuitions provide at least initial reason for thinking that there really are natural laws and specifically distinct natural kinds. In more Hegelian terms, they provide initial support for the reality of something — laws and kinds—-that 
does not show up in perception, but is accessible to further "thought" about our observations. Hegel says:

Inasmuch as it is said that ... mind and nature have universal laws to which their life and changes conform, then it is conceded that the determinations of thought equally have objective value and existence. (WL 5:45/51)

Similarly, if one accepts the intuition that we ourselves can explain at least some natural phenomena by appealing to natural laws, then this will provide initial reason to think that we have at least some knowledge of natural laws and kinds. And if the metaphysical view that reality contains no necessary connections is unsupported and rules out the possibility of such knowledge, then why not take this as at least initial reason to reject that metaphysical view? ${ }^{34}$

Hegel also continues from his discussion of empiricism, in the opening sections of the Encyclopedia, to treat Kant's critical philosophy as a subvariety of one general "position of thought with respect to objectivity." He interprets Kant's claims about the "bounds of experience," then, as indebted to broadly empiricist commitments. ${ }^{35}$ But it is important that Kant has a distinctive argument of his own in support of his claims about the bounds of experience: Our cognition is finite, in the sense that we lack divine or intellectual intuition which grasps reality immediately and all at once; therefore we must be limited to the knowledge possible for a “discursive” understanding — or an understanding dependent for all intuition on sensibility, and so restricted by the limits of what can be presented in sensible intuition. ${ }^{36}$ If this argument is successful, then it will provide reason to accept any further consequences, even if the consequences about laws and kinds could be shown to be counter-intuitive. But the suppressed premise is any such argument is that the distinction between the two kinds of intellect is exhaustive, so that our lack of one type establishes that we are limited to the other. And Hegel's initial example of knowledge of natural laws and kinds suggests that Kant's basic distinction rather a false dichotomy. For such knowledge exceeds what Kant allows as possible for a discursive understanding dependent on sensible intuition, and yet it does not require a divine grasp of reality immediately and all at once. Perhaps if there were independent reason to think that laws only describe or summarize universal regularities, then there would also be reason to think that knowledge of laws would require experiencing everything, or divine intuition grasping all of nature immediately and all at once, so as to gain knowledge of which regularities do hold universally. But Hegel rejects this conception of natural laws. And Hegel provides an initial account on which our knowledge of natural laws and kinds is not immediate, but specifically requires the "mediation" (§22) of experience and further thinking about it—so much mediation that empiricists are bound to complain. Hegel's account of our knowledge of natural laws and kinds does not require him to deny that our knowledge is always mediated in some way. It requires him to deny Kant's claim that our knowledge is always mediated in one and the same specific sense: that it is always mediated or conditioned by the limits of what can be presented in sensible intuition, and so mediated specifically by the forms of space and time.

In sum, the opening sections of the Encyclopedia provide-in response to the most obvious reasons for doubt, and to Kant's reasons for doubt-initial support for the claims that there are natural laws governing determinate natural kinds, and that we can have knowledge of these (with no special restriction to only a maximally abstract or general kind like matter). 


\section{The Ambitions of Hegel's Theoretical Philosophy}

It is now possible to understand the general sense in which Hegel seeks to show that we can have knowledge of things as they are in themselves. Hegel argues from the beginning that we can have knowledge beyond the bounds of experience; insofar as there are objects of such knowledge, there are objects beyond Kant's bounds. More specifically, there are a variety of "universal determinations," of which natural laws and kinds are initial cases. For example, perhaps gold and mercury are natural kinds whose interaction is governed by a natural law. If so, then to come to know that these are the kinds of substances we observe, and to know the law governing their reaction, is to progress from the sensible features of things to knowledge of their more fundamental features - to knowledge of those features which explain what happens when these substances come into contact. Kant can allow that we approximate such insight; perhaps we know well enough from experience what we can likely expect when this stuff touches that stuff. But Kant must deny us knowledge that gold and mercury really are the natural kinds governed by the natural law which truly necessitates or determines what happens here. He must deny that we can have here the sort of knowledge we are supposed to have of the sensible features of the objects of experience. Insofar as such explanatory knowledge would be knowledge of a law governing of specifically distinct kinds, it would be knowledge surpassing Kant's bounds of experience. It would be, in this sense, knowledge of things as they are in themselves. Alternatively, insofar as this knowledge explains, or answers why-questions, it is knowledge of interest to reason. In Hegel's terms, then, he seeks to show that we can have knowledge of "the thing in itself, to use the Kantian expression-or rather the reasonable" (WL 5:60-1/63-4).

Hegel most commonly expresses this point by means of his surprising use of the term "concept" (Begriff). Adequate explanation of that term would require a separate study. But we can at least note that Hegel uses that term to refer to the sorts of "universal determinations" we have been discussing, including especially the general natural kinds governed by universal natural laws. For example, in discussing chemistry Hegel uses the term "concept" to refer to chemical kinds, or "the universal essence, the real kind (Gattung) of the particular object" (WL 6:430/728). Such "universal determinations" or "concepts" are not supposed to be separate entities inhabiting a separate ontological realm of universals. They are rather "immanent":

the nature, the peculiar essence, that which is genuinely permanent and substantial in the complexity and contingency of appearance and fleeting manifestation, is theconcept (Begriff) of the thing, the immanent universal (WL 5:26/36).

So Hegel's Begriffe, including initially natural kinds governed by universal laws, are not minddependent in the sense we would expect given the term "concept": the reality and the real effective impact of laws governing natural kinds does not depend on their being represented by us. They are not mind-dependent, but they are accessible only to thought: universal determinations are not present as such in experience; we must actively think further about experience in order to separate out and grasp the universal aspects, or the Begriffe, as such. ${ }^{37}$

Note however that Hegel's goal, in seeking to establish knowledge beyond Kant's limits, is not to establish knowledge of an absolutely unconditioned and unified totality of everything — nor to 
establish knowledge of anything accessible only to divine intuition grasping reality immediately and all at once. $\frac{38}{}$ It remains Hegel's ambition to dismiss the very idea of objects knowable only by divine intuition, such as "that absolute of which we know nothing except that in it all is one"; "things in themselves" in this sense are supposed to be "nothing but truthless, empty abstractions." This ambition is supposed to be compatible with the one announced in the very next sentence: the Logic aims to establish knowledge of things in themselves in the sense sketched immediately above-knowledge of the more fundamental features of things which explain their behavior. For example, knowledge of the natural kinds in virtue of which different things are governed by necessary laws. More generally, this is knowledge of "what something is in its Begriff':

What, however, the thing in itself is in truth, what truly is in itself, of this logic is the exposition, in which however something better than an abstraction is understood by 'in itself', namely, what something is in its concept (in seinem Begriffe).

And the two ambitions will be compatible so long as Hegel can show that the all the Begriffe or "universal determinations" he introduces are not accessible only to divine intuition, but are-as he immediately adds—“comprehensible” (begreiflich) and "cognizable” (erkennbar) (WL 5:130/121).

Furthermore, Hegel's two ambitions here are not merely compatible; together they define a unified project in theoretical philosophy, or a unified, extended argument-strategy. To see how, recall Kant's “Transcendental Dialectic” argument. Kant argues that we can have knowledge only within the bounds of experience. And the faculty of reason is supposed to be unsatisfied by any such knowledge, and to seek the very opposite: we can have knowledge, mediated by the forms of our sensible intuition, of objects conditioned in space and time; reason seeks knowledge of the unconditioned, which would be possible only for intellectual intuition grasping reality immediately and all at once. Insofar as we cannot know but must conceive of the unconditioned, we must conceive it as "present in things insofar as we are not acquainted with them, as things in themselves" — and so must conclude that our knowledge is limited or restricted (Bxx).

But if Hegel is right that we can have explanatory knowledge beyond Kant's bounds of sense, beginning with knowledge of natural laws governing specifically distinct kinds, then why continue to hold that the pursuit of explanatory insight must always seek a form of knowledge in principle unavailable to us? Hegel will argue that reason's goal, by contrast, must not by understood as something knowable only by divine intuition grasping reality immediately and all at once. If Hegel can account for reason's goal without appeal to anything like Kant's distinction between two utterly distinct kinds of intellect, then he can further show that there is no in principle barrier between our own knowledge and the kind of knowledge we seek in all theoretical inquiry. If so, then Hegel can undermine Kant's conclusion that such a barrier forces us to hold that our own knowledge is fundamentally limited or restricted, or that we can have no knowledge of things as they are in themselves. Or, Hegel can eliminate Kant's reasons for thinking that we must take seriously the idea of objects of intellectual intuition. So Hegel seeks to surpass one Kantian limit precisely in order to eliminate another: he seeks to show that our 
explanatory knowledge so far exceeds Kant's bounds of experience that no need remains to conceive of objects of divine intuition, relative to which we would be merely limited. Hegel seeks to establish knowledge of things in themselves (in the first sense) precisely in order to dismiss the whole idea of things in themselves (in the second).

We can already anticipate that one general line of Hegelian argument toward this end will focus on determinacy. To see the point, first consider one of Hegel's arguments against the form of monism sketched above: Say we begin by holding that everything real must be grounded in an absolutely unified and unconditioned totality or whole. Hegel will argue that such an absolutely unified and unconditioned totality could not ground any determinate, differentiated or diverse phenomena. So if nothing can be real that is not so grounded, then monists of this sort are supposed to be forced to conclude (whatever their intentions) that all determinate, differentiated or diverse phenomena are unreal. For example, Spinoza is supposed to lose "all determinate content" into an "abyss"; the same point applies to those of Hegel's contemporaries who assert that there is an "absolute" in which "all is one." ${ }_{39}$ It would of course require more attention to adequately explain, let alone to defend, this line of argument. But the introductory sections of the Encyclopedia clearly aim to prepare for that argument: Hegel here claims that philosophy must set aside "abstract principles," such as "in the absolute all is one," in favor of the determinacy provided by the "empirical sciences," which have "prepared the material for philosophy by finding universal determinations, kinds, and laws” (§12An).

And it is easy to see how Hegel aims to argue, from here, that the goal by which reason guides our theoretical inquiry cannot be anything akin to knowledge of an absolutely unified and unconditioned totality. If the object of such knowledge would be too abstract or indeterminate explain the determinate phenomena of the world, then clearly this cannot be what we are seeking when we pursue explanatory insight into such phenomena. Perhaps the goal of reason is akin to what Kant calls a "systematic unity of nature.” But, if so, then the systematic unity of nature would have to differ in important respects from an unconditioned totality of everything. It would have to be, at least in respect of its determinacy, more akin to the natural laws governing specifically distinct natural kinds. But, if so, then we lose Kant's reasons for claiming that the knowledge which reason seeks would be knowledge possible only for divine intuition. And then conceiving of the goal of theoretical inquiry will not require us to entertain or take seriously the conception of objects knowable only by divine intuition. In Hegel's terms, Kant's argument for the limitation of our knowledge depends on taking the goal of reason to be the unconditioned in the sense of something opposed to or other than the determinate. Hegel says:

Our empirical cognitions are not appropriate for this identity that lacks determinations altogether ... When an unconditioned of this sort is accepted as the absolute and the truth of reason (or as the idea), then, of course, our empirical awareness is declared to be untrue, to be appearance. (§45)

But if Hegel can justify an alternative account of the goal of reason, as something that is determinate and not accessible only to divine intuition, then he can eliminate Kant's grounds for taking seriously the idea of divine intuition and its objects, leaving us without grounds for thinking that we are limited to knowledge of appearance, or that we cannot know things as they are in themselves. 
To be sure, the proof is in the pudding, and I have focused here only on Hegel's introduction of his project. Hegel's execution naturally raises many further issues not touched on here. For example, Hegel's initial case for the reality and knowability of natural laws governing specifically distinct kinds does not get much beyond defending, against empiricist and Kantian worries, some natural intuitions about laws, kinds and explanation. But Hegel's criticism of appeals to immediate knowledge, supposed to require no justification, will require him to provide more than initial intuitions. It will require him to extend from here to some more robust philosophical defense of the reality and knowability of "universal determinations," including first of all the natural kinds and laws discussed here.

Second, understanding Hegel's execution would require attention to his arguments that there are limitations of natural laws and kinds, or limitations of his own introductory examples of "universal determinations" or Begriffe - and in particular to his argument, against Kant, that we can have access to a more complete form of explanatory knowledge insofar as we can explain the structure and development of living beings in teleological terms.‥ My own view is that Hegel is not here arguing that the whole of everything is itself an organism, or teleologically organized. Rather, he is arguing that reality consists of distinct and determinate levels, arranged hierarchically and corresponding with different forms of explanation—so that, for example, everything is composed of material parts explicable in mechanistic terms, and some (not all) matter is also part of living beings explicable in teleological terms. We are supposed to be able to gain knowledge of the whole of everything, then, not by breaking through to a higher standpoint from which an otherwise hidden unity of the whole becomes apparent, but rather by pursuing a form of philosophical inquiry into different levels of explanation and the relations between them. But, needless to say, this material and these issues require separate discussion.

And third, Hegel's execution is supposed to achieve a philosophical benefit not discussed here: If Hegel can successfully break the connection between the goal of reason and divine intuition, then he can try to justify reason's pursuit of that goal by showing that there is some sense in which the world itself answers to such pursuit. This kind of justification would no longer need to involve any assertion of knowledge accessible only to divine intuition. And this is just what Hegel seeks to do. In Hegel's terms, "reason" does not just refer to a faculty of ours, which sets or projects a goal for us to seek; it refers to the ideal form of intelligibility of which theoretical inquiry generally seeks knowledge. And Hegel seeks to demonstrate that the world answers to "reason" in this sense; he seeks to show that this sort of ideal intelligibility or "reason" is realized "in the world." " Insofar as this means showing that a goal or standard providing the point of absolutely all theoretical inquiry is itself not merely a goal of ours, but is realized in the world, Hegel seeks to defend an account of what he calls simply "the absolute."”2 But I have not discussed here Hegel's reasons for thinking that philosophy should and even must pursue such an account, so that the lack of an account of "the absolute" would be an important philosophical disadvantage of competing views - so that Kant's denial of the possibility of knowledge of the reality of the objects ultimately of interest to reason would turn out to be a philosophical disadvantage.

My point here, however, has not been to follow the execution of Hegel's project. The point is rather that following Hegel's execution will require first an understanding of the basic goals of his project in theoretical philosophy. And this understanding can be impeded if we limit 
ourselves to debating whether Hegel's project involves a revival or rather a rejection of the kinds of metaphysical ambitions criticized by Kant. For it is essential to Hegel's project that it involves both. More specifically, if Kant's distinction between intellectual intuition and the finite discursive understanding is a false dichotomy, then we can naturally understand the target of Kant's criticisms in two different ways. On the one hand, we can see Kant's critical revolution as targeting metaphysics in the sense of accounts which assert knowledge of divine intuition, or knowledge that there really is some highest being accessible only to a divine grasp of reality immediately and all at once. Hegel embraces Kant's critical revolution, understood in this manner, and so rejects claims that the totality of all reality might be a unified whole providing an unconditioned ground for everything real. Hegel specifically complains that most of his contemporaries merely revert to such uncritical forms of metaphysics. On the other hand, we can also understand the critical revolution as targeting metaphysics in the sense of accounts which assert knowledge of objects beyond Kant's bounds of experience. Perhaps some contemporary philosophers find appealing the idea of entirely rejecting "metaphysics" in this second sense. But this is no reason to view Hegel through such a contemporary lens, or to prefer a "nonmetaphysical" reading. Rather, we must recognize that Hegel seeks to establish the reality and knowability of objects beyond Kant's bounds of sense. Hegel ambitiously violates Kant's restrictions on metaphysics (in the second sense) specifically in order to complete what he sees as Kant's unfinished revolution the metaphysics of divine intuition (metaphysics in the first sense): Hegel seeks to defend an account of things as they are in themselves specifically designed to eliminate all remaining role or room for the idea of a divine immediate grasp of reality —even and especially the Kantian role of articulating the goal of reason and the limitation of our knowledge. 


\section{Primary Texts and Abbreviations}

Kant: I use the translations of Kant's works in the Cambridge Edition of the Works of Immanuel Kant, altering where necessary, and citing according to the following abbreviations:

$\mathrm{A} / \mathrm{B}=$ Critique of Pure Reason (Guyer-Wood translation 1998); MAN=Metaphysical Foundations of Natural Science (Friedman 2002); KU=Critique of the Power of Judgment(Guyer-Mathews translation 2000); UE=“On a Discovery...” (Allison translation 2002 in Theoretical Philosophical after...); TP= "On a Recently Prominent Tone...” (Heath translation 2002 in Theoretical Philosophical after...). VR="Lectures on the Philosophical Doctrine of Religion" (Wood translation 1996 in Religion and Rational Theology); Ak=Deutsche Akademie der Wissenschaften edition of Kants gesammelte Schriften (Berlin: Walter de Gruyter, 1902ff). Except for the first Critique A/B pagination, all page references are to AK volume:page. Translations altered where necessary.

Hegel: I use the following abbreviations and translations, altering where necessary: $\S=$ Encyclopedia Logic (Geraets, Harris and Suchting translation 1991, Hackett); PG=Phenomenology of Spirit (Miller translation 1977, OUP); WL= Science of Logic (Miller translation [1969] 1989, Humanities Press); VGP=Lectures on the History of Philosophy (Haldane-Simson translation 1995, University of Nebraska Press); W=Suhrkamp edition of Hegel's Werke (edited by Moldenhauer-Michel) 1970-1. In the case of the case of the Encyclopedia I cite § number, and 'An' indicates Hegel's remarks, 'Zu' indicates the Zusätze. In all other cases I cite from W volume:page followed by the volume (if applicable) and page in the English translation listed here. Translations altered where necessary.

Schelling: DMS=Presentation of my System of Philosophy (Vater translation 2001 in Philosophical Forum 32:4, 339-71). Cited by volume:page from Sämmtliche Werke, ed. K.F.A. Schelling, Stuttgart: Cotta, 1856-61.

\section{Other References}

Allison, H. E. (2004) Kant's Transcendental Idealism: An Interpretation and Defense, Revised and Enlarged Edition (New Haven: Yale University Press).

Ameriks, K. (1990) “Kant, Fichte, and short arguments to idealism” Archiv für Geschichte der Philosophie, 72, pp. 63-85.

Armstrong, D. M. (1983) What Is A Law of Nature? (Cambridge: CUP). 
Ameriks, K. (2003) Interpreting Kant’s Critiques (Oxford: Clarendon Press).

Baum, M. (1990) “Kants Prinzip der Zweckmäßigkeit und Hegels Realisierung des Begriffs", in: Hegel und die Kritik der Urteilskraft. Ed. H. F. Fulda und R. P. Horstmann. pp. 139-157. Stuttgart.

Brandom, R. (1999) "Some Pragmatist Themes in Hegel's Idealism”, European Journal of Philosophy, 7: 164-189.

Beiser, F.C. (2005) Hegel (New York: Routledge).

Beiser, F.C. (1993) "Hegel and the problem of metaphysics" in The Cambridge Companion to Hegel (Cambridge: CUP).

Dretske, F. (1977) “Laws of nature” Philosophy of Science 44: pp. 248-68.

Düsing, K. (1986) "Ästhetische Einbildungskraft und intuitiver Verstand. Kants Lehre und Hegels spekulativ-idealistische Umdeutung.” Hegel-Studien. 21, pp. 87-128.

Edwards, J. (2000) Substance, Force and the Possibility of Knowledge: On Kant's Philosophy of Material Nature (Berkeley: University of California Press).

Friedman, M. (1992a) “Causal laws and natural science.” In The Cambridge Companion to Kant. Paul Guyer (ed.) (Cambridge: CUP).

Friedman, M. (1992b) Kant and the Exact Sciences. (Cambridge: Harvard University Press.)

Friedman, M. (2001) "Matter and motion in the Metaphysical Foundations and the first Critique: The Empirical Concept of Matter and the Categories". In Kant and the Sciences. Ed. E. Watkins. 53-69. (New York: Oxford University Press).

Friedman, M. (2006) “Kant, skepticism, and idealism.” Inquiry 49:1 pp. 26-43.

Gram, Moltke S. (1981) "Intellectual intuition: the continuity thesis." Journal of the History of Ideas 42, pp. 287-304.

Guyer, P. (1990) "Kant's conception of empirical law” in Proceedings of the Aristotelian Society, Supplementary Volume 64: pp. 220-242.

Horstmann, R. P. (1991) Die Grenzen der Vernunft. Eine Untersuchung zu Zielen und Motiven des Deutschen Idealismus, Frankfurt am Main.

Horstmann, R. P. (2006a). “Hegels Ordnung der Dinge. Die Phänomenologie des Geistes als ,transzendentalistisches' Argument für eine monistische Ontologie und seine erkenntnistheoretischen Implikationen” Hegel-Studien 41.

Horstmann, R. P. (2006b) "Hegel's Phenomenology of Spirit as an argument for a monistic ontology.” Inquiry 49:1 pp. 103-118. 
Kitcher, P. (1986) "Projecting the order of nature” in Kant's Philosophy of Physical Science, ed. R.E. Butts. Dordrecht: Reidel.

Kreines, J. 2004. “Hegel’s critique of pure mechanism”, European Journal of Philosophy. 12:1, 38-74.

Kreines, J. forthcoming. “The Logic of Life: Hegel’s Philosophical Defense of Teleological Explanation in Biology.” The Cambridge Companion to Hegel, second edition, edited by F. Beiser.

Longuenesse, B. (2000) "Point of view of man or knowledge of god” In The Reception of Kant's Critical Philosophy. Fichte, Schelling, and Hegel, Sally Sedgwick (ed.) (Cambridge: CUP).

McDowell, J. (1996) Mind and World (Cambridge: Harvard University Press).

Nayak, A. C. and Sotnak, E. (1995) "Kant on the impossibility of the 'soft sciences"” Philosophy and Phenomenological Research 55: pp. 133-151.

Okruhlik, K. (1986) "Kant on realism and methodology" in Kant's philosophy of physical science, ed. R.E. Butts. (Dordrecht: Reidel).

Pinkard, T. (1996) "What is the non-metaphysical reading of Hegel ? A Reply To F Beiser”. 34: 13-20.

Pippin, R. (1989) Hegel's idealism (Cambridge: CUP).

Redding, P. (2002) “Georg Wilhelm Friedrich Hegel”, The Stanford Encyclopedia of Philosophy, Edward N. Zalta (ed.)

$<$ http://plato.stanford.edu/archives/sum2002/entries/hegel/>.

Spinoza, B. (1994) A Spinoza Reader, ed. and trans. Edwin Curley. Princeton.

Stern, R. (1990) Hegel, Kant and the Structure of the Object. London ; New York: Routledge.

Westphal, K. R. (1989a) "Hegel's attitude toward Jacobi in the 'Third Attitude of Thought Toward Objectivity’” Southern Journal of Philosophy 27: pp. 135-156.

Westphal, K. R. (1989b) Hegel’s Epistemological Realism. (Dordrecht: Kluwer).

Westphal, K. R. (2000) “Kant, Hegel, and the fate of 'the' intuitive intellect'” in the Reception of Kant’s Critical Philosophy. Ed. Sedgwick, Sally. (Cambridge: CUP).

Westphal, K. R. (2004) Kant’s Transcendental Proof of Realism. (Cambridge: CUP). 
1 On Hegel as advocating a modification of Spinoza's monism, see Horstmann (2006a; 2006b; 1991 165ff.) and Beiser (2005; 1993).

2 Hegel “accepts much of Kant's criticism of the 'dogmatic' tradition” (Pippin 1989, 9); he seeks not a metaphysically realist account of "being as it is in itself" (97) but to render "epistemically idle” Kant's "skepticism" concerning things in themselves (250). Also Pinkard (1996). And compare McDowell on eliminating boundaries from within: e.g. "it is central to Absolute Idealism to reject the idea that the conceptual realm has an outer boundary" $(1994,44)$.

$\underline{3}$ Kant refers to "everything intuited in space and time, hence all objects of an experience possible for us" (A490-1/B519-20). Note that the categories do not delimit the bounds of experience; they could, in themselves, legitimately extend farther if given another source of intuition (B148).

4 On the synthetic status of the principles of the understanding, and the connection to temporality, see Allison (2004, 225-8).

$\underline{5}$ See the "Second Analogy," and with respect to space: "reality in space, i.e. matter, is likewise something conditioned, whose inner conditions are its parts" (A413/B440).

6 A428/B456, A432/B460; A486/B514.

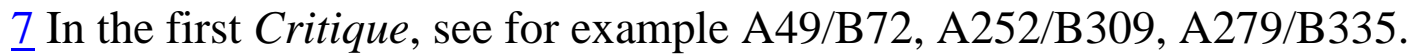

$\underline{8} \mathrm{KU} \S \S 76-7$. For similar earlier consideration in terms of parts and wholes see (Ak 18:131-2), cited by Gram (1981, 293).

$\underline{9}$ See e.g. B68 and B145, and Gram’s (1981) argument that Kant's different claims about intellectual intuition do not cohere.

10 A490-1/B518-9 and see also A369 and A28-30/B44-5.

11 Ameriks 1990. Note that the point of transcendental idealism itself is not that "objects can be intelligible only as 'relative' to the concepts, or systems of concepts, or theories, that we 'impose'” (Ameriks 2003, 102). Kant does hold that all knowledge of objects requires concepts (A51/B75). But "transcendental idealism" itself concerns the limitation or restriction imposed specifically by our sensible intuition and its specific forms. But to insist on this point is not to commit to any response to further controversies about how transcendental idealism is to be further understood, for example, whether it involves any ontological claims about the real existence of unknowable entities. 
12 Some who address Hegel's development interpret his late work as transforming Kant's idea of an "intuitive understanding” (Baum 1990, 173; Düsing 1986, 125 and Longuenesse 2000, 234). Insofar as this means that Hegel's late work aims to establish knowledge beyond what is possible for a "discursive" understanding, as described by Kant, it is undoubtedly correct. But it is equally important that Hegel's late work does not aim to assert the reality of anything knowable only by grasping reality immediately and all at once. I take suchimmediacy to be central to Kant's idea of an "intuitive understanding," so I would not describe Hegel as preserving the central positive content of that Kantian idea. For Kant on the connection between this idea and the sort of immediacy rejected by Hegel, see e.g. "the understanding of God is intuitive ... this being must rather intuit all things immediately through its understanding, and cognize everything at once” (VR 28:1051).

13 VGP 20:434-5/3:525. On this line of argument see Westphal 1989a and 2000.

14 These passages are from VGP 20:327/3:421 and EL, §41Zu 8:115/82, respectively, with the emphasis in both added by me. Here I agree emphatically with the Kantian readings: "Hegel accepts much of Kant's criticism of the 'dogmatic' tradition, and in particular rejects a reliance on the classical notion of intellectual intuition” (Pippin 1989, 9). And see Pinkard (1996, 14). See also Redding: "The very opposition that Kant has between finite human thought and infinite godly thought is suspect” (2002, section 3.2).

15 Recall Kant's formulation: "we had to have in mind another possible intuition if we were to hold our own to be a special kind, namely one that is valid of objects merely as appearances” (KU 5:406).

16 Hegel associates monism of this sort with Spinoza (W 16:99) and with Schelling and his followers (PG 3:22/9; §12An; WL 5:120/113; 5:130/121). I do not defend Hegel's interpretations here, but with respect to Spinoza note his argument that substance is indivisible (Ethics IP13), and his clarification in terms of a distinction between two ways of grasping substance: substance as known by intellect as opposed to imagination is indivisible (Ethics IP15S). With respect to Schelling see: "if we could view everything that is in the totality, we would perceive ... a pure identity in which nothing is distinguishable" (DMS 4:128). And this "absolute identity" is "unconditioned," (DMS 4:119) and the "ground of reality” (DMS 4:146).

17 Hegel recognizes that Kant is defending "objective" knowledge in the sense of knowledge of "what is externally present, as distinct from what is only subjective, meant, dreamed, etc" (§41Zu). 
18 Kant aims to justify teleological judgment specifically as "a heuristic principle for researching the particular laws of nature, even granted that we would want to make no use of it for explaining nature itself" (KU 5:411). Kant denies the possibility of our explaining living beings or anything natural in teleological terms (also KU 5:360 and 5:417).

$\underline{19}$ On causality and causal laws, see A91/B124. more generally, "this necessity of laws is inseparably attached to the concept of nature” (MAN 4:469).

20 Reflexion 5414 (Ak 18:176), cited by Friedman (1992a, 175). Also see B3-4 and MAN 4:468.

21 See e.g. Allison's response to Strawson and others (2004, 254ff.), and Friedman's response to Allison and others (1992a).

22 There is interpretive disagreement about the precise nature of the connections to $a$ priori intuition; see Friedman (2001).

23 MAN 4:471, see also 4:468, and Friedman (1992a, 189).

24 On the importance of reducibility, I agree with Nayak and Sotnak (1995, 147-150). Note that in MAN Kant is not optimistic about the prospects for such progress in chemistry, though he is more optimistic in the last years of his life; see Friedman 1992b, 264ff.

$\underline{25}$ On this limit see especially Friedman 1992a, on this passage specifically at p. 190.

$\underline{26}$ "We cannot speak of proving those 'laws'. The claim that they legislate for unactualized possibilities is always fallible" (Kitcher 1986, 230). "Fully determinate knowledge of empirical laws can never be more than a regulative ideal” (Guyer 1990, 222). And see the citations from Friedman in the next note below.

$\underline{27}$ See especially Friedman (1992a, 190 and 2006, 34).

28 Westphal argues that the doctrine of "transcendental affinity" - and the connected "law of genera" from the appendix to the "Transcendental Dialectic"-conflicts with Kant's transcendental idealism (Westphal 2004, 87ff.) and with Kant's own official view of the limits of our a priori knowledge (100), anticipating a later "post-critical" phase (174). See also Edwards (2000). I do not seek to defend or to presuppose any claims here about the Opus postumum.

$\underline{29}$ DS 2:104/164. Watkins (2003) presents a similar dilemma for Kant. 
30 See the citation from $\S 21 \mathrm{Zu}$ in the following paragraph, and also: nature "is unalterably governed (regiert) by universal laws” (W 12:23).

$\underline{31}$ See for example the argument of "Sense Certainty" in the Phenomenology.

32 Hegel refers here to his earlier argument, in the "Relation of Skepticism to Philosophy," for the superiority of ancient to modern skepticism which is not skeptical about "feeling and intuition" (§39).

33 For contemporary use of similar terms, see Beebee (2000) on the "descriptive" or "non-governing" conception of laws, and Loewer "it is more apt to say" that laws "summarizeevents" (1996, 114).

34 Similar arguments show up in recent philosophy: First, the explanatory import of laws rules out Humean accounts of natural laws (Dretske 1977; Armstrong 1983, 401). Second, Humean accounts must be rejected specifically because they would rule out the possibility of our having knowledge of natural laws (1983, 52ff.).

$\underline{35}$ E.g. Kant adopts a "Humean standpoint, the standpoint that proclaims the thinking of our perceptions to be inadmissible; i.e. the eliciting of the universal and necessary out of these perceptions” (§50). Hegel is over-reaching here: Kant holds that such thinking is necessary and justified, denying only that it yields theoretical knowledge of determinate universal laws; but this denial is what Hegel seeks to overturn.

36 For example, Kant argues in this way to limit the extent to which the categories allow knowledge at (B309/A253). On the central role of discursivity in Kant, and on this as the basic argument in support of it, see especially Allison (2004, 14ff.).

37 On this activity of thought, see $\S 21 \mathrm{ff}$. For more on Hegel on immanent universals, see especially Westphal (1989b, ch. 10) and Stern (1990).

$\underline{38}$ For this reason, although I agree with Friedman's account of a post-Kantian dissatisfaction with what came to seem an "intolerable skepticism" in Kant's position, I think it important to resist giving a common interpretation Hegel's and Schelling's responses (2006, 34). Hegel's response needs to be understood in light of his criticisms of what he sees as the most popular responses of his contemporaries, including Schelling.

39 §151Zu. On Spinoza see also WL 5:121/214; 5:179/161. On the absolute in which all is one, see PG 3:22/9. 
40 See especially this series of sections near the end of the Logic: "Mechanism", "Chemism”, "Teleology”, and "Life." I provide an account of Hegel's argument for the priority of teleology over mechanism in (Kreines 2004); and an account of Hegel's defense of natural teleology in (Kreines forthcoming).

$\underline{41}$ §24An; also e.g. W 12:23; VGP 18:369.

$\underline{42}$ Note for example Hegel's use of the term “absolute” in discussing Kant’s account of reason and the unconditioned at $\S \S 44-5$.

43 For comments on and assistance with this material, I thank audiences at the Central APA; Claremont McKenna College; Cornell University; University of California, Irvine; and the University of Kansas. I also benefited from editorial and referee comments provided by this journal, and also comments from: Andrew Chignell, Michael Della Rocca, Robert Guay, Simon Lumsden, Jamie Martin, Robert Pippin, Paul Redding, and Allen Wood.

Correspondence Address: James Kreines, Philosophy Department, Yale University, PO Box 208306, New Haven CT 06511, USA. Email: james.kreines@yale.edu 